\title{
Development System for Reducing Fuel Consumption with Logarithmic Approach for Aperture Valve System on Throttle Body
}

\author{
Muhamad Farhan $^{1 *}$, Mohamad Ramdhani $^{1}$, and Estananto ${ }^{1}$ \\ ${ }^{1}$ Electrical Engineering, Electrical Department, 40257 Telkom University, Indonesia
}

\begin{abstract}
Decreasing of petroleum reserve and increasing of fossil fuel consumed lead to an energy crisis. To anticipate that case, it is required for the development of modified motor vehicles to optimize fuel consumption. A modification toward the valve on the throttle body regulating the mixed amount of the incoming gasoline and air into the combustion chamber can be an alternative solution of the case. By changing the valve aperture system which has initially been linier become logarithmic with the gas handle, make the mixture of incoming gasoline and air into the combustion chamber more efficient. In this research Motorcycle Carburettor $110 \mathrm{cc}$ is used. The result of the research shows that the fuel consumption can be optimized to $37 \%$ lower consumption compared to normal mode.
\end{abstract}

\section{Introduction}

Recently, there are many motorized vehicles operating in our daily life either as public transportation, delivery of goods, or just as a personal transportation [1]. A huge hike on increasing number of vehicles will have a great impact on fuel consumption, and because fossil fuel is still dominant, it will cause big problem due to limited petroleum resources [2]. More petroleum is being consumed, however in the other hand the reserve is scarcer. This might be one of the causes of rising price fuel, and it can make operational cost of vehicle rising [2]. Therefore, it is necessary to develop a system that can save the use of fuel to optimize the daily operational costs as well as to improve environmental impact of fossil fuel consumption.

In the automotive industry some efforts have been widely developed on fuel efficiency of automobile, such as throttle by wire (TBW) system that can focus on fuel efficiency and comforting while driving [3], In this research, a new approach is developed that focuses on fuel efficiency of two-wheeled vehicle with small cubical centimeter (cc), By modifying the valve aperture system which has initially been linier to logarithmic one with the gas handle, the mixing process of incoming gasoline and air into the combustion chamber can

\footnotetext{
${ }^{1}$ Corresponding author: m.farhanmlt@gmail.com
} 
be more efficient, which in turn can optimize daily operational costs and improving environment quality.

\section{Performance Parameters of The Machine}

Specific Fuel Consumption (SFC), also known as Thrust-Specific Fuel Consumption (TSFC), is the fuel efficiency of engine to spend energy for an hour.

$$
m_{f}=\frac{\operatorname{sgf} \cdot V_{f} \cdot 3600}{1000 \cdot t_{f}}\left(\frac{\mathrm{Kg}}{\mathrm{Hour}}\right)
$$

where $m_{f}$ is fuel consumption ( $\mathrm{kg} /$ hour $), \mathrm{sgf}$ is specific gravitation $(\mathrm{gr} / \mathrm{ml})$ which has a value 0.715 , Vf is volume of tested fuel $(\mathrm{ml})$, $\mathrm{tf}$ is time to deplete tested fuel (seconds).

\section{Design and Application}

Figure 1 describes the overall system block diagram. In this diagram, it can be seen that the accelerator uses a resistance changing sensor to provide an input signal to the microcontroller and it controls the motor servo to open the valve of the throttle body. The opening valve in the throttle body will affect the least amount of air and gasoline mixture into the combustion chamber. The process is shown in Fig. 1 and Fig. 2.

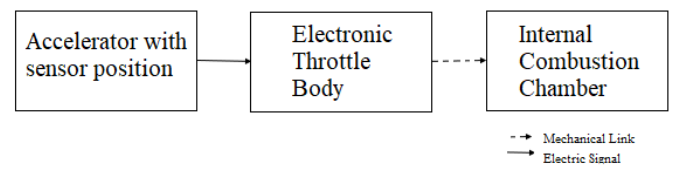

Fig. 1 Electronic Throttle System

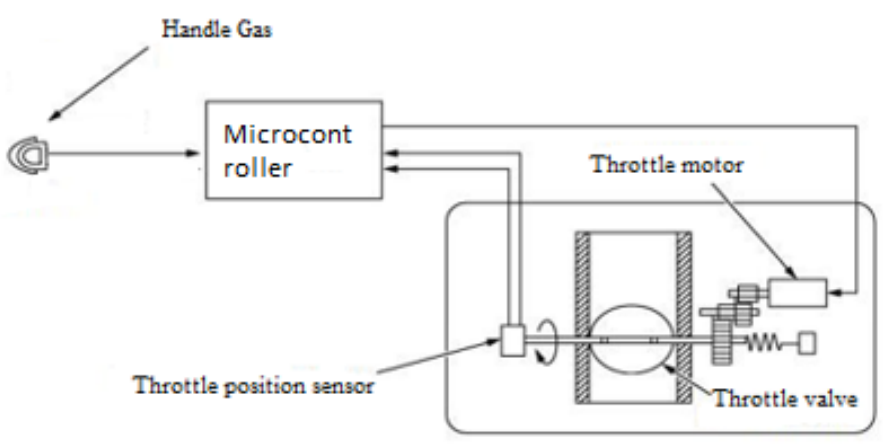

Fig. 2 Design System

By modifying the position on the accelerator, it will change the resistances from 0 $1000 \mathrm{Ohm}$, then the value is read by the microcontroller to be processed, and output from microcontroller makes the motor servo working in two modes: linear or logarithmic, depending on which mode has been chosen for opening valve on the throttle body. The two modes are depicted in figure 3. 

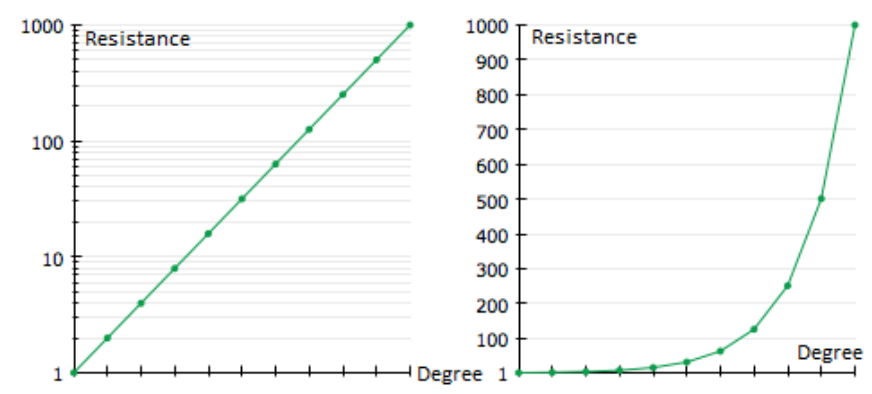

Fig. 3 Curve Changing Degree of Valve Opening System

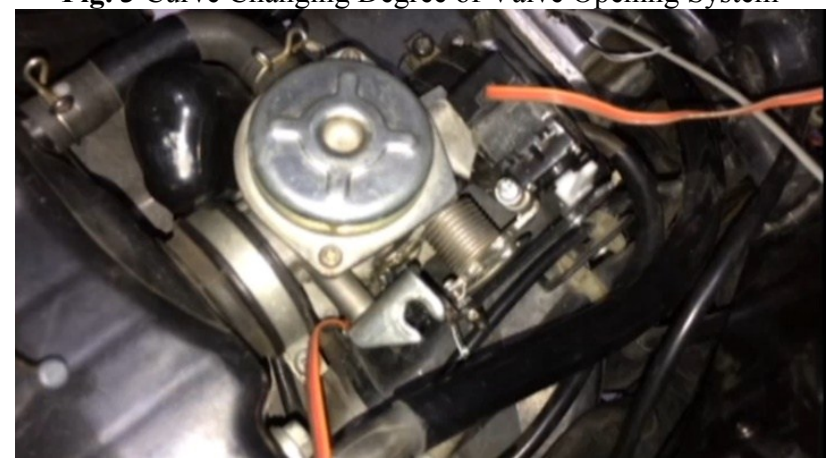

Fig. 4 Installation of System

\section{Test Results and Discussion}

Before the system is installed, the motorbike under test is tested and the test data is taken. Under normal circumstances the motorbike is able to travel surrounding the field forming 1100-meter circumference circle. The motorbike's specification is $110 \mathrm{cc}$ carburettor engine type and the fuel consumed is 1.05 litter Pertamina's Pertamax 92octane gasoline. Rider's weight about $68 \mathrm{~kg}$. The engine temperature after the vehicle is turned on for 5 minutes.

One day after, the test of the engine with the new proposed system with logarithmic opening valve with the same vehicle and same condition is conducted. At that time, experiment with efficient mode shows significant improved result, with no negative impact during the test. The engine works well and the system runs stable. Data is displayed in Figure 7-10.

The difference in average speeds obtained after the collection of test data between the two systems found that the speed traveled per round ranges from 30 to $40 \mathrm{~km} / \mathrm{h}$, but at the time of the round to 19 vehicles that use normal mode cannot run again due to exhausted gasoline, while vehicles that use efficient mode can still drive up to 31 rounds. 


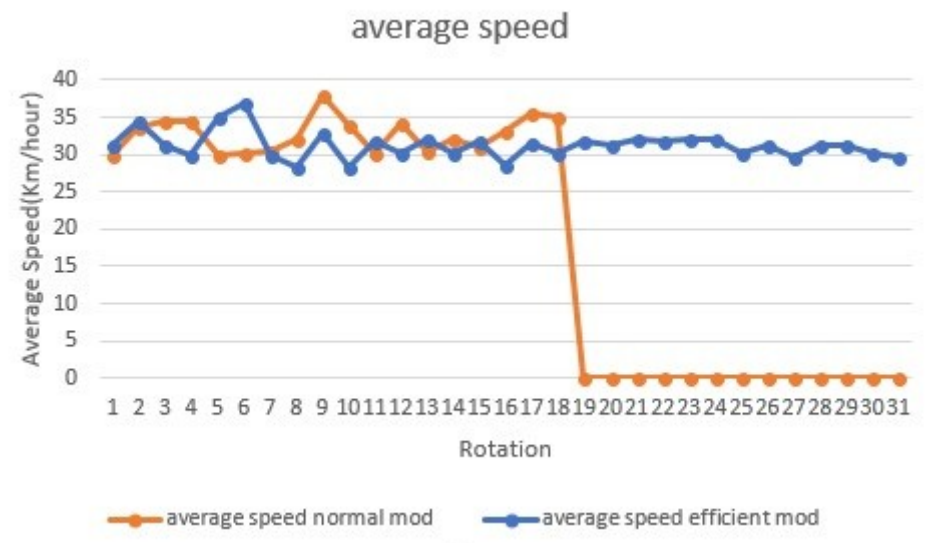

Fig. 5 Comparing average speed between two modes

Distance used when sampling ranges is between 1080 meters until 1100 meters, with the same Distance of vehicles with normal mode can only travel as much as 18 rounds.

\section{Distance}

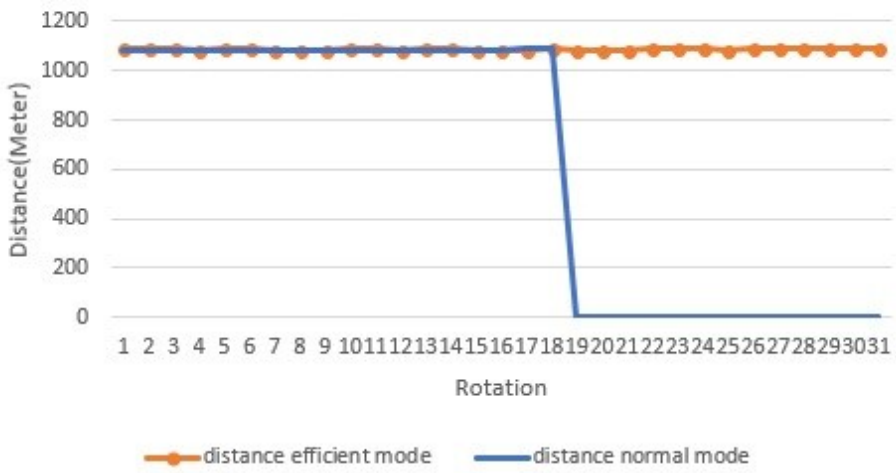

Fig. 6 Comparing Mileage between two modes

With an average speed of $30 \mathrm{~km} / \mathrm{h}-40 \mathrm{~km} / \mathrm{h}$, the distance to round the track as far as $1100 \mathrm{~m}$ is ranging between 120 - 140 seconds. Vehicles with normal mode can only travel as much as 18 rounds while vehicles using the efficient mode can still go up to 31 rounds. 


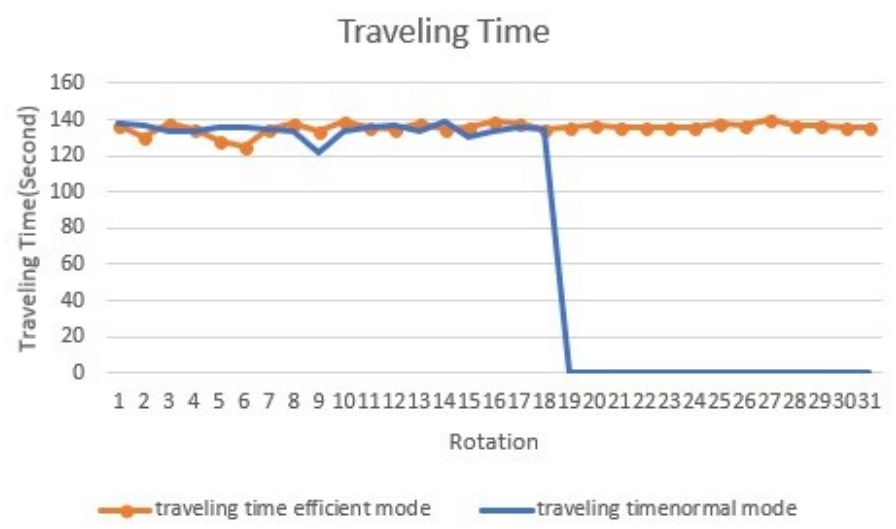

Fig. 7 Comparing Traveling time needed between two modes

\section{Conclusion}

According to the results obtained from the efficient mode installation it can be seen that, by using efficient mode, a vehicle with $110 \mathrm{cc}$ carburettor type can save fuel usage up to 31 rounds with a distance of $33 \mathrm{~km}$, in comparison in normal mode it can only take 18 rounds or $19 \mathrm{~km}$, both with fuel consumption of 1 litter of Pertamax. If we calculate the figures based on fuel consumption per hour $\left(m_{f}\right)$ then we can know the fuel consumption while using efficient mode is only 0.86 liter/hour, in comparison with 1.36 liter/hour in normal mode. This is $37 \%$ saving of fuel consumption in comparable same condition.

\section{Future Works}

Further improvement is needed to implement the proposed system in various type of motorcycles in larger scale. This concept can save up to millions of litres of fuel consumption, billion rupiah in operating costs, and can reduce much air pollution.

\section{References}

1. Giulio Panzani, Matteo Corno, Sergio M. Savaresi, "Design of an Adaptive Throttle-by-Wire Control System for a Sport Motorbike," International Federation of Automatic Control (IFAC), Sept (2011)

2. Xiong Fang, Wenwu Mao, Xisheng Shen, Jianyu LI, Wenchao Huang and Zhixin Chen, "The Quantum Energy Saver design and Fuel-saving application," IOP Conf. Series: Materials Science and Engineering 157, Aug (2016)

3. Pratik Parsania, Ketan Saradava, "Drive-By-Wire Systems In Automobiles," Conference: Journal of systematic computing, (VVP Engineering, 2012)

4. [4] Abhishek Kumar, Abhijeet Kumar, Ujjwal Ashish, Ashok B (2016). Design of Electronically Controlled Fuel Injection System For Carburetor Based Engine. IJRET(International Journal of Research in Engineering and Technology) ,Volume: 05 ,Special Issue: 03, SYNERGY-2016, Mar (2016)

5. T.Balasubramani, S.Jeyapaul, K.Karthick, M.Karthick, G.Manikandan (2016). Fuel Efficiency in A Petrol Engine by Using Water Injection. IJLTET(International Journal of Latest Trends In Engineering And Technology), Volume 6, Issue :04 